\section{JURNAL EKONOMI EFEKTIF}

ISSN : $2622-8882$, E-ISSN : 2622-9935

Jurnal Ekonomi Efektif, Vol. 4, No. 1, Oktober 2021 @ Prodi Manajemen Fakultas Ekonomi Universitas Pamulang

\title{
PENGARUH PELAYANAN PURNA JUAL TERHADAP LOYALITAS KONSUMEN PADA DEALER PIAGIO VESPA DI KOTA TANGERANG SELATAN
}

\author{
Anri Ani ${ }^{1}$, Fadhilah Hanifah ${ }^{2}$, Vita Stefanya Christina ${ }^{3}$, Sewaka $^{4 *}$ \\ Universitas Pamulang, Tangerang Selatan, Banten, Indonesia \\ anryani05@gmail.com ${ }^{1}$, fadhilahhanie@gmail.com² stfnya@outlook.com³ $^{3}$, \\ dosen00120@ unpam.ac.id ${ }^{4 *}$
}

Manuskrip: Agustus -2021; Ditinjau: September: -2021; Diterima: September-2021; Online: Oktober-2021; Diterbitkan: Oktober-2021

\begin{abstract}
ABSTRAK
Penelitian ini bertujuan untuk mengetahui pengaruh pelayanan purna jual terhadap loyalitas konsumen pada Dealer Piagio Vespa di Kota Tangerang Selatan. Metode yang digunakan adalah explanatory research dengan sampel sebanyak 96 responden. Teknik analisis menggunakan analisis statistik dengan pengujian regresi, korelasi, determinasi dan uji hipotesis. Hasil penelitian ini variabel pelayanan purna jual diperoleh nilai rata-rata skor sebesar 3,414 dengan kriteria baik. Variabel loyalitas konsumen diperoleh nilai rata-rata skor sebesar 3,830 dengan kriteria baik. Pelayanan purna jual berpengaruh positif dan signifikan terhadap loyalitas konsumen dengan nilai persamaan regresi $Y=9,636+0,840 \mathrm{X}$, dan nilai koefisien korelasi 0,771 atau memiliki tingkat hubungan yang kuat dengan nilai determinasi $59,4 \%$. Uji hipotesis diperoleh signifikansi $0,000<0,05$.
\end{abstract}

Kata Kunci: Pelayanan Purna Jual, Loyalitas Konsumen

\section{ABSTRACT}

This study aims to determine the effect of after-sales service on consumer loyalty at Piagio Vespa Dealers in South Tangerang City. The method used is explanatory research with a sample of 96 respondents. The analysis technique uses statistical analysis with regression, correlation, determination and hypothesis testing. The results of this research variable after sales service obtained an average score of 3,414 with good criteria. The consumer loyalty variable obtained an average score of 3.830 with good criteria. After-sales service has a positive and significant effect on consumer loyalty with the value of the regression equation $Y$ $=9.636+0.840 X$, and the correlation coefficient value of 0.771 or has a strong relationship with a determination value of 59.4\%. Hypothesis testing obtained a significance of 0.000 $<0.05$.

Keywords: After Sales Service, Consumer Loyalty 


\section{PENDAHULUAN}

\section{A. Latar Belakang Masalah}

Pada era bisnis saat ini, persaingan dalam aktivitas usaha mengalami peningkatan seiring dengan meningkatnya kemajuan ilmu pengetahuan, teknologi dan transportasi. Kondisi saat ini persaingan semakin kompetitif dengan memanfaatkan teknologi yang semakin canggih, serta perubahan pada konsumen yang mulai pintar dan terdidik untuk memilih dan membandingkan pelayanan. Untuk itu kegiatan pemasaran yang baik dan tepatlah yang memegang peranan yang penting dalam menunjang kelangsungan usaha dan perkembangan suatu perusahaan. Dengan kata lain pihak produsen harus mampu merebut hati konsumen akan hasil suatu produksi yang dijaul dan berupaya untuk mempertahankan pelanggannya.

Tingkat persaingan di dunia otomotif yang semakin ketat saat ini membuat perusahaan otomotif senantiasa harus berusaha untuk merebut market share (pangsa pasar) dan mempertahankan pelanggan yang sudah ada. Untuk itu kegiatan pemasaran yang baik dan tepatlah yang memegang peranan yang penting dalam menunjang kelangsungan usaha dan perkembangan suatu perusahaan. Dengan kata lain pihak produsen harus mampu merebut hati konsumen akan hasil suatu produksi yang dijual dan berupaya untuk mempertahankan pelanggannya.

Semakin banyaknya jumlah pengguna sepeda motor, untuk itulah secara tidak langsung konsumen juga membutuhkan sarana dan prasarana untuk merawat maupun memperbaiki kendaraannya tersebut agar layak pakai, tidak kalah dengan produk baru dan dapat dijual dengan harga yang tinggi. Hal ini menimbuklan persaingan yang ketat terutama pada penyedia jasa service antara dealer resmi yang bekerjasama dengan merkmerk sepeda motor tertentu yang saling bersaing untuk mendapatkan kosumen. Oleh karena itu penyedia jasa lebih meningkatkan tujuan yang lebih baik yakni bagaimana cara menumbuhkan konsumen yang puas atas jasa yang diberikan ke arah konsumen yang loyal.

Secara harfiah loyal berarti setia dan loyalitas diartikan sebagai suatu kesetiaan. Kesetiaan ini sesuatu yang timbul tanpa ada paksaan tapi timbul dari kesadaran sendiri. Menurut Kotler dan Keller (2014:207) "loyalitas adalah komitmen yang dipegang teguh untuk membeli kembali atau berlangganan produk pilihan atau jasa di masa depan meskipun pengaruh situasional dan upaya pemasaran memiliki potensi untuk menyebabkan konsumen beralih ke produk lain".

Loyalitas menurut Griffin (2010:04), adalah "seorang konsumen dikatkan setia atau loyal apabila konsumen menunjukan perilaku pembelian secara teratur atau terdapat suatu kondisi dimana mewajibkan konsumen membeli paling sedikit dua kali dalam selang waktu tertentu".

Suatu perusahaan harus dapat merancang strategi pemasaran yang tepat dalam mencapai tujuan perusahaan, salah satu tujuan perusahaan itu adalah mencipatakan loyalitas pelanggan. Agar terciptanya loyalitas pelanggan maka suatu perusahaan harus menetapkan strategi pemasaran yang baik, misalnya dengan kualitas harga dan pelayanan purna jual yang baik dapat menciptakan kepuasan konsumen.

Dalam konsep pemasaran, kepuasan konsumen merupakan suatu keharusan. Sehingga proses pemasaran tidak hanya berhenti pada transaksi penjualan. Lebih dari itu, salah satu hal yang sangat penting dan perlu diperhatikan oleh produsen adalah pemberian layanan purna jual.

Seperti menurut Hollensen (2010:397) yang menjelaskan bahwa "layanan purna jual didefinisikan sebagai kegiatan-kegiatan dimana perusahaan bergerak setelah pembelian produk yang meminimalkan potensi masalah yang terkait dengan penggunaan 
produk dan memaksimalkan nilai dari pengalaman konsumsi". Para peneliti telah menyarankan bahwa pelayanan purna jual yang terdiri dari sejumlah elemen. Di sini, layanan purna jual dikonsep terdiri dari instalasi dan start up dari produk yang dibeli, penyediaan suku cadang untuk produk, penyediaan layanan perbaikan, saran teknis mengenai produk, dan ketentuan dan dukungan garansi.

Philip Kotler (2014:508) mengatakan "Layanan purna jual adalah layanan yang diberikan perusahaan kepada seorang konsumen setelah terjadinya transaksi penjualan".

Sedangkan menurut Hindle dan Thomas dalam Fandy Tjiptono (2015:32) menyatakan bahwa "Layanan purna jual adalah suatu layanan yang disediakan oleh produsen kepada konsumen setelah konsumen tersebut membeli produk dari perusahaan tersebut".

Layanan purna jual yang baik akan memberikan kontribusi yang baik terhadap para konsumen. Hal ini dapat dimanfaatkan Piaggio Vespa untuk menangani masalah loyalitas pelanggan yang cenderung cukup rendah.

PT. Premier International merupakan salah satu perusahaan yang bergerak di bidang otomotif yaitu dealer resmi sepeda motor Piaggio Vespa di wilayah Serpong. Selain menjual motor Piaggio Vespa dengan berbagai tipe dan model, PT Premier International juga menyediakan bengkel pemeliharaan dan perbaikan Piaggio Vespa. Jika dibandingkan dengan merk-merk motor lain, Piaggio Vespa dapat dikatakan berbeda, karena Piaggio Vespa memiliki harga yang relatif lebih tinggi. Selain itu Piaggio Vespa menjadi salah satu transportasi yang modern sejak tahun 1946 sampai saat ini. PT Premier International selalu mengutamakan konsistensi dalam menjaga kualitas pelayanan purna jual untuk mempertahankan loyalitas para pelanggannya.

Dengan meningkatnya persaingan yang ada, perusahaan harus mengetahui faktorfaktor yang mempengaruhi loyalitas pelanggannya agar dapat melakukan perbaikan dan inovasi yang diharapkan dapat meningkatkan loyalitas pelanggan di PT Premier International Serpong. Salah satunya adalah dengan menyediakan fasilitas pendukung bagi pelanggan agar merasa terlayani dengan baik.

Dalam hal ini suku cadang dan aksesoris merupakan hal yang paling mendasar dalam pelayanan purna jual yang mana hal tersebut bisa mejadi jaminan pelanggan dalam hal pemeliharaan dan perawatan sepeda motor untuk waktu yang akan datang. Oleh karena itu penyediaan suku cadang dan aksesoris adalah salah satu indikator yang memegang peran penting dalam usaha untuk memuaskan pelanggan, dimana pada akhirnya akan membantu mempertahankan loyalitas pelanggan yang telah dimiliki.

Untuk mengetahui tingkat loyalitas pelanggan di PT Premier International, penulis sebelumnya telah melakukan pra penelitian dan mendapatkan hasil bahwa jumlah pelanggan yang melakukan service di bengkel PT Premier International cenderung tidak stabil dan cenderung menurun, kondisi seperti ini penulis menduga sebagai akibat dari layanan purna jual yang diberikan perusahaan masih belum maksimal.

Berdasarkan data yang telah diuraikan maka penulis merasa tertarik untuk melakukan penelitian dengan judul "Analisis Pelayanan Purna Jual Terhadap Loyalitas Pelanggan Pada Dealer Piaggio Vespa di Kota Tangerang Selatan”.

\section{B. Rumusan Masalah}

1. Bagaimana pelayanan purna jual pada Dealer Piagio Vespa di Kota Tangerang Selatan ?.

2. Bagaimana loyalitas konsumen pada Dealer Piagio Vespa di Kota Tangerang Selatan ?.

3. Adakah pengaruh antara pelayanan purna jual terhadap loyalitas konsumen pada 
Dealer Piagio Vespa di Kota Tangerang Selatan ?.

\section{Tujuan Penelitian}

1. Untuk mengetahui kondisi pelayanan purna jual pada Dealer Piagio Vespa di Kota Tangerang Selatan.

2. Untuk mengetahui kondisi loyalitas konsumen pada Dealer Piagio Vespa di Kota Tangerang Selatan.

3. Untuk mengetahui pengaruh pelayanan purna jual terhadap loyalitas konsumen pada Dealer Piagio Vespa di Kota Tangerang Selatan.

\section{TINJAUAN PUSTAKA}

\section{Pelayanan purna jual}

Yang dimaksud dengan pelayanan purna jual adalah layanan yang diberikan perusahaan kepada seorang konsumen setelah terjadinya transaksi penjualan Philip Kotler (2014:508)

\section{Loyalitas konsumen}

Yang dimaksud dengan loyalitas adalah seorang konsumen dikatkan setia atau loyal apabila konsumen menunjukan perilaku pembelian secara teratur atau terdapat suatu kondisi dimana mewajibkan konsumen membeli paling sedikit dua kali dalam selang waktu tertent, Griffin (2010:31).

\section{METODE PENELITIAN}

\section{Populasi}

Populasi dalam penelitian ini berjumlah 96 responden Dealer Piagio Vespa di Kota Tangerang Selatan

\section{Sampel}

Teknik pengambilan sampling dalam penelitian ini adalah sampel jenuh, dimana semua anggota populasi dijadikan sebagai sampel. Dengan demikian sampel dalam penelitian ini sampel yang digunakan berjumlah 96 responden.

\section{Jenis Penelitian}

Jenis penelitian yang dipakai adalah asosiatif, dimana tujuannya adalah untuk mengetahui atau mencari keterhubungan antara variabel independen terhadap variabel dependennya

\section{Metode Analisis Data}

Dalam menganalisis data digunakan uji validitas, uji reliabilitas, analisis regresi linier sederhana, analisis koefisien korelasi, analisis koefisien determinasi dan pengujian hipotesis.

\section{HASIL PENELITIAN}

\section{Analisis Deskriptif}

Pada pengujian ini digunakan untuk mengetahui skor minimum dan maksimum skor tertinggi, ratting score dan standar deviasi dari masing-masing variabel. Adapun hasilnya sebagai berikut:

Tabel 1. Hasil Analisis Descriptive Statistics

\section{Descriptive Statistics}

\begin{tabular}{lr|r|r|r|r} 
& N & \multicolumn{1}{c}{ Minimum } & Maximum & Mean & \multicolumn{1}{c}{ Std. Deviation } \\
\hline Pelayanan purna jual (X) & 96 & 28 & 44 & 34.14 & 3.914 \\
\hline Loyalitas konsumen (Y) & 96 & 29 & 49 & 38.30 & 4.265 \\
\hline Valid N (listwise) & 96 & & & & \\
\hline
\end{tabular}


Pelayanan purna jual diperoleh varians minimum sebesar 28 dan varians maximum 44 dengan ratting score sebesar 3,414 dengan standar deviasi 3,914. Skor ini termasuk pada rentang sakala 3,40 - 4,19 dengan kriteria baik atau setuju.

Loyalitas konsumen diperoleh varians minimum sebesar 29 dan varians maximum 49 dengan ratting score sebesar 3,830 dengan standar deviasi 4,265. Skor ini termasuk pada rentang sakala 3,40 - 4,19 dengan kriteria baik atau setuju.

\section{Analisis Kuantitatif}

Pada analisis ini dimaksudkan untuk mengetahui pengaruh variabel independen terhadap variabel dependen. Adapun hasil pengujian sebagai berikut:

\section{a. Analisis Regresi Linier Sederhana}

Uji regresi ini dimaksudkan untuk mengetahui perubahan variabel dependen jika variabel independen mengalami perubahan. Adapun hasil pengujiannya sebagai berikut:

\begin{tabular}{|c|c|c|c|c|c|}
\hline \multirow[b]{3}{*}{ Model } & \multicolumn{2}{|c|}{ Coefficients $^{\mathrm{a}}$} & \multirow{3}{*}{$\begin{array}{l}\text { Standardized } \\
\text { Coefficients } \\
\text { Beta }\end{array}$} & \multirow[b]{3}{*}{$\mathrm{t}$} & \multirow[b]{3}{*}{ Sig. } \\
\hline & \multicolumn{2}{|c|}{$\begin{array}{l}\text { Unstandardized } \\
\text { Coefficients }\end{array}$} & & & \\
\hline & B & Std. Error & & & \\
\hline 1 (Constant) & 9.636 & 2.461 & & 3.915 & .000 \\
\hline Pelayanan purna jual (X) & .840 & .072 & .771 & 11.723 & .000 \\
\hline
\end{tabular}

Berdasarkan hasil pengujian pada tabel di atas, diperoleh persamaan regresi $\mathrm{Y}$ $=9,636+0,840 X$. Dari persamaan tersebut dijelaskan sebagai berikut:

1) Konstanta sebesar 9,636 diartikan jika pelayanan purna jual tidak ada, maka telah terdapat nilai loyalitas konsumen sebesar 9,636 point.

2) Koefisien regresi pelayanan purna jual sebesar 0,840 , angka ini positif artinya setiap ada peningkatan pelayanan purna jual sebesar 0,840 point maka loyalitas konsumen juga akan mengalami peningkatan sebesar 0,840 point.

\section{b. Analisis Koefisien Korelasi}

Analisis koefisien korelasi dimaksudkan untuk mengetahui tingkat kekuatan hubungan dari variabel independen terhadap variabel dependen. Adapun hasil pengujian sebagai berikut:

Tabel 3. Hasil Pengujian Koefisien Korelasi Pelayanan purna jual Terhadap Loyalitas konsumen.

\section{Correlations $^{\text {b }}$}

\begin{tabular}{llr|r} 
& & \multicolumn{1}{c}{$\begin{array}{c}\text { Pelayanan } \\
\text { purna jual (X1) }\end{array}$} & \multicolumn{1}{c}{$\begin{array}{c}\text { Loyalitas } \\
\text { konsumen (Y) }\end{array}$} \\
\hline Pelayanan purna jual (X) & Pearson Correlation & 1 & $.771^{* *}$ \\
\cline { 2 - 4 } & Sig. (2-tailed) & & .000 \\
\hline Loyalitas konsumen (Y) & Pearson Correlation & $.771^{* *}$ & 1 \\
\cline { 2 - 4 } & Sig. (2-tailed) & .000 & \\
\hline
\end{tabular}

Berdasarkan hasil pengujian diperoleh nilai korelasi sebesar 0,771 artinya pelayanan purna jual memiliki hubungan yang kuat terhadap loyalitas konsumen.

\section{c. Analisis Koefisien Determinasi}

Analisis koefisien determinasi dimaksudkan untuk mengetahui besarnya persentase pengaruh dari variabel independen terhadap variabel dependen. Adapun hasil pengujian sebagai berikut: 
Tabel 4. Hasil Pengujian Koefisien Determinasi Pelayanan purna jual Terhadap Loyalitas konsumen.

Model Summary

\begin{tabular}{|c|c|c|c|c|}
\hline \multicolumn{5}{|c|}{ Moder Summary } \\
\hline Model & $\mathrm{R}$ & R Square & $\begin{array}{l}\text { Adjusted R } \\
\text { Square }\end{array}$ & $\begin{array}{l}\text { Std. Error of the } \\
\text { Estimate }\end{array}$ \\
\hline 1 & $.771^{\mathrm{a}}$ & .594 & .590 & 2.733 \\
\hline
\end{tabular}

Berdasarkan hasil pengujian diperoleh nilai determinasi sebesar 0,594 artinya pelayanan purna jual memiliki kontribusi pengaruh sebesar 59,4\% terhadap loyalitas konsumen, sedangkan sisanya sebesar $40,6 \%$ dipengaruhi oleh faktor lain yang tidak dilakukan penelitian.

\section{d. Uji Hipotesis}

Pengujian hipotesis dengan uji t digunakan untuk mengetahui hipotesis mana yang diterima.

Rumusan hipotesis: Terdapat pengaruh yang signifikan pelayanan purna jual terhadap loyalitas konsumen.

Tabel 5. Hasil Uji Hipotesis Pelayanan purna jual Terhadap Loyalitas konsumen.

\begin{tabular}{|c|c|c|c|c|c|}
\hline \multirow[b]{2}{*}{ Model } & \multicolumn{2}{|c|}{$\begin{array}{l}\text { Coefficients }^{\mathbf{a}} \\
\text { Unstandardized } \\
\text { Coefficients }\end{array}$} & \multirow{2}{*}{$\begin{array}{c}\text { Standardized } \\
\text { Coefficients } \\
\text { Beta } \\
\end{array}$} & \multirow[b]{2}{*}{$\mathrm{t}$} & \multirow[b]{2}{*}{ Sig. } \\
\hline & $\mathrm{B}$ & Std. Error & & & \\
\hline 1 (Constant) & 9.636 & 2.461 & & 3.915 & .000 \\
\hline Pelayanan purna jual (X) & .840 & .072 & .771 & 11.723 & .000 \\
\hline
\end{tabular}

Berdasarkan hasil pengujian pada tabel di atas, diperoleh nilai t hitung $>\mathrm{t}$ tabel atau $(7,809>1,989)$, dengan demikian hipotesis yang diajukan bahwa terdapat pengaruh yang signifikan atara pelayanan purna jual terhadap loyalitas konsumen diterima.

\section{Pembahasan Hasil Penelitian}

\section{Kondisi Jawaban Responden Variabel Pelayanan purna jual}

Berdasarkan jawaban responden, variabel pelayanan purna jual diperoleh ratting score sebesar 3,414 berada di rentang skala 3,40 - 4,19 dengan kriteria baik atau setuju.

\section{Kondisi Jawaban Responden Variabel Loyalitas konsumen}

Berdasarkan jawaban responden, variabel loyalitas konsumen diperoleh ratting score sebesar 3,830 berada di rentang skala 3,40-4,19 dengan kriteria baik atau setuju.

\section{Pengaruh Pelayanan purna jual Terhadap Loyalitas konsumen}

Pelayanan purna jual berpengaruh signifikan terhadap loyalitas konsumen dengan persamaan regresi $\mathrm{Y}=9,636+0,840 \mathrm{X}$, nilai korelasi sebesar 0,771 atau memiliki hubungan yang kuat dengan kontribusi pengaruh sebesar 59,4\%. Pengujian hipotesis diperoleh nilai $t$ hitung $>t$ tabel atau $(7,809>1,989)$. Dengan demikian hipotesis yang diajukan bahwa terdapat berpengaruh signifikan antara pelayanan purna jual terhadap loyalitas konsumen diterima.

\section{KESIMPULAN DAN SARAN}

\section{Kesimpulan}

a. Variabel pelayanan purna jual diperoleh ratting score sebesar 3,414 berada di rentang skala 3,40-4,19 dengan kriteria baik atau setuju.

b. Variabel loyalitas konsumen diperoleh ratting score sebesar 3,830 berada di rentang skala 3,40-4,19 dengan kriteria baik atau setuju. 
c. Pelayanan purna jual berpengaruh signifikan terhadap loyalitas konsumen dengan persamaan regresi $\mathrm{Y}=9,636+0,840 \mathrm{X}$, nilai korelasi sebesar 0,771 atau kuat dan kontribusi pengaruh sebesar 59,4\% sedangkan sisanya sebesar 40,6\% dipengaruhi faktor lain. Uji hipotesis diperoleh nilai t hitung $>t$ tabel atau $(7,809>1,989)$.

\section{Saran}

Berdasarkan hasil penelitian di atas, maka penulis memberikan saran sebagai berikut:

a. Perusahaan harus melakukan pelatihan yang terprogram utamanya pada teknisi, sebab teknisi menjadi ujung tombak dalam memberikan layanan purnajual kepada konsumen. Sehingga ketrampilan mereka menangani keluhan konsumen sangat menentukan kepuasan konsumen.

b. Perusahaan harus selalu memberikan layanan terbaik. kualitas pelayanan yang baik adalah cara pertama yang harus Anda lakukan untuk membuat pelanggan loyal terhadap bisnis perusahaan

\section{DAFTAR PUSTAKA}

Algifari. (2015). "Analisis Regresi untuk Bisnis dan Ekonomi”. Yogyakarta: BPFE.

Arikunto, Suharsimi (2014). "Prosedur Penelitian Suatu Pendekatan Praktek". Kota Tangerang Selatan: Rineka Cipta.

Bashu Swastha dan T. Handoko (2015) Manajemen Pemasaran Moderen, Yogyakarta: BPFE.

Basu Swastha Dharmmesta. (2014). Manajemen Pemasaran. BPFE: Yogyakarta. Buchari Alma. 2014. Manajemen pemasaran dan Pemasaran Jasa. Edisi Revisi.

Bilson Simamora (2016) Panduan Riset Prilaku Konsumen, Kota Tangerang Selatan: PT. Gramedia Pustaka.

Erlangga, H., et al.(2021). Pengaruh Kualitas Pelayanan Dan Kualitas Produk Terhadap Keputusan Pembelian Konsumen Sepeda Motor Honda Di PT Panca Sakti Perkasa Di Bintaro. Jurnal Ilmiah PERKUSI, 1(4), 464-472.

Fandy Tjiptono (2017), Serivce Quality and Satisfiation. Kota Tangerang Selatan: Edisi tiga. Andi.

Freddy Rangkuti (2016) Strategi Promosi Yang Kreatif, Edisi Pertama, Cetakan Pertama Kota Tangerang Selatan: Gramedia Pustaka Utama.

Imam Ghozali (2017). “Aplikasi Analisis Multivariate Dengan Program SPSS". Edisi Kelima. Semarang: Badan Penerbit Undip.

Istijanto (2014) "Riset Sumber Daya Manusia”. Kota Tangerang Selatan: PT. Gramedia Pustaka

Kharis, Ismu Fadli (2011). "Studi Mengenai Impulse Buying dalam Penjualan Online”. Semarang : Skripsi Universitas Diponegoro

Kotler dan Amstrong (2017), Prinsip-prinsip Pemasaran. Edisi Kedua Belas”. Jilid Satu. Kota Tangerang Selatan: Erlangga.

Lupiyoadi (2016) Manajemen Pemasaran Jasa, Edisi 4, Kota Tangerang Selatan: Salemba Empat.

Mani, J. (2017). Pengaruh Persepsi Merek Dan Pelayanan purna jual Terhadap Kepuasan Pelanggan (Studi Kasus Pada PT. Bisma Narendra Di Kota Tangerang Selatan). Jurnal Mandiri, 1(2), 187-206.

Nurjaya, N., et al. (2021). Pengaruh Brand Image Terhadap Keputusan Pembelian Pada PT. Wahana Motor Di Wilayah Cianjur. Jurnal Ilmiah PERKUSI, 1(2), 291-296.

Philip Kotler (2017) Manajemen Pemasaran, Edisi Keempat Belas, Kota Tangerang Selatan: PT. Indeks. 
Phipil Kotler dan Kevin Keller (2017) Manajemen Pemasaran, Edisi Kedua Belas, Jilid Satu, Kota Tangerang Selatan: Erlangga.

Rao, Purba, (2012). "Measuring Consumer Perceptions Through Factor Analysis", The Asian.

Rofianto, W., et al. (2021). Cultural Product Branding, Antecedents, And Its Implications: A Study On The Context Of Indonesian Batik. International Journal Of Social, Policy And Law, 2(2), 37-46.

Santoso, Singgih (2015). “Menguasai Statistik Multivariat”. Kota Tangerang Selatan: PT Elex Media Komputindo.

Sudjana (2014) “Metode Statistika”, Bandung: Tarsido.

Sugiyono (2017), "Metode Penelitian Administrasi : dilengkapi dengan Metode $R \&$ D”. Bandung: Alfabeta.

Suhartanto (2014). “Metode Riset Pemasaran”. Bandung: Alfabeta

Wangsi, M. M., et al. (2018). Perlindungan Konsumen Dalam Pelabelan Produk Menurut Ekonomi Islam. Sentralisasi, 7(1), 1-9. 